\title{
SCImago Journal Rank Indicator: A Viable Alternative to Journal Impact Factor for Dental Journals
}

\author{
Khalid Mahmood (corresponding author) \\ Department of Information Management, \\ University of the Punjab, Lahore, Pakistan \\ khalid.im@pu.edu.pk \\ Khalid Almas \\ College of Dentistry, \\ University of Dammam, Saudi Arabia \\ kalmas@uod.edu.sa
}

\begin{abstract}
Objective. This paper investigated the possibility of SCImago Journal Rank (SJR) indicator as an alternative to the Journal Impact Factor (JIF) in the field of dentistry.

Method. The SJR and JIF scores and ranking order of 88 dental journals were downloaded from the relevant websites. Pearson and Spearman correlation coefficients were calculated to test hypotheses for association between the two journal quality metrics.

Result. A very strong positive correlation was found between the scores and ranking order based on the SJR and JIF of selected journals. Hence, academics and researchers in dentistry can use the SJR indicator as an alternative to JIF.
\end{abstract}

\section{INTRODUCTION}

Assessment of research quality is an important activity in all academic and professional fields. Citation-based evaluation metrics have been the most common method in the last few decades. As the only provider of citation data, the Institute for Scientific Information (now Thomson Reuters) has a long-established monopoly of the market. The Journal Impact Factor (JIF), first conceived in 1955 by Eugene Garfield, was the main quantitative measure of quality for scientific journals. The JIFs, published annually in the Journal Citation Reports (JCR), are widely used for quality ranking of journals and extensively used by leading journals in their advertising (Elsaie \& Kammer, 2009). The JIFs are also used for a variety of other purposes. "For instance, it is used by librarians as a criterion for selecting library collections. JIF is also used by researchers to decide where they will submit their research manuscripts. JIF also serves as an evaluation tool by institutions for recruitment, promotion, research grant allocation, and project funding” (Law \& Li, 2015, p. 19). “The JIF is generally defined as the recorded number of citations within a certain year (for example, 2015) to the items published in the journal during the two preceding years (2013 and 2014), divided by the number of such items (this would be the equivalent of the average citation rate of an item during the first and second calendar year after the year of publication). Only citations between journals indexed in the Thomson Reuter's Web of Science (WoS) are used (Cantin, Munoz \& Roa, 2015, pp. 1183-1184). 
The JCR Journal Impact Factor maintains its monopoly to date and is considered the best instrument for the ranking of journals. At the same time it has been a victim of severe criticism. Many authors have challenged the methodology of JIF calculation (Rieder, Bruse, Michalski, Kleeff, \& Friess, 2010; Rossner, Van Epps \& Hill, 2007; Seglen, 1997). "Whilst all citations for the given year are taken into account as the numerator, only manuscripts deemed to be original research or review papers, by employees of the company are included in the denominator. This in turn has resulted in poor reproducibility of the calculated impact factor which often serves as a source of conflict between publishers, editors and the ISI" (Oosthuizen \& Fenton, 2014, p. 241). Other demerits of JIF include its bias towards English language publications, the disparity between different specialties and subspecialties, limited number of journals, and the inclusion of journal's self-citations (Cantin, Munoz \& Roa, 2015; Elliot, 2014; Falagas \& Alexiou, 2008; Falagas, Kouranos, Arencibia-Jorge, \& Karageorgopoulos, 2008; Oosthuizen \& Fenton, 2014; San Francisco DORA, 2012). In the light of these criticisms, there is a need for an alternative to JIF.

SCImago Research Laboratory in 2007 developed the SCImago Journal Rank (SJR) indicator, a journal quality indicator that uses Scopus-indexed journals for quality assessment, applying the Google's PageRank algorithm on the Scopus database. More complex than JIF, it considers citations in a three-year period (Cantin, Munoz \& Roa, 2015). The SJR allows not only citation counts, but also works as an indicator of importance and influence of citing journals (Khurshid, 2014). The Scopus database contained over 21,500 journals and periodical publications in its directory (Scopus, 2016), which is substantially more comprehensive than the JCR (11,000+ indexed journals) (Journal Citation Reports, 2016). "The journal's self-citation rate is limited to a maximum of 33\%, a measure that effectively excludes manipulation through the use of self-citation” (Oosthuizen \& Fenton, 2014, p. 242). A further advantage of the SJR is its free availability on the Internet while the JCR is a commercial product.

In the present study, we calculated the correlation between JIFs and SJRs of dental journals and journal rankings based on these two quality metrics. The objective was to see whether SJR scores and rankings based on them were comparable with the gold standard of JIF, and whether SJR could be an alternative to JIF for deciding publication, scientific reading and other uses of journal ranking in the field of dentistry.

\section{METHODS}

We identified journals in the JCR category Dentistry, Oral Surgery \& Medicine and downloaded the latest available Journal Impact Factors (JIF-2015) as well as the ranking data. Similarly, we downloaded SJR scores (latest for 2015) for journals in the subject category Dentistry from the website SCImago.com.

JIF scores were found for 89 dental journals included in the JCR. In the SCImago, there were 170 journals in this category. We selected 88 JCR based journals for comparison and further analysis. Note that five JCR journals were not included in the dentistry list by SCImago. One JCR journal was not found in SCImago. The other four were found in the category Medicine.

We set the following null hypotheses to test in this study:

- $\mathrm{H}_{0} 1$ : There is no correlation between the SCImago Journal Rank indicator and the Journal Impact Factor of dental journals.

- $\mathrm{H}_{0}$ 2: There is no correlation between journal rankings based on the SJR and the JIF of dental journals. 
We compared JIF and SJR scores as well as ranking based on them for selected journals with the help of Microsoft Excel (version 2010). The correlation coefficients for two sets of paired data were calculated using IBM SPSS software (version 21).

\section{RESULTS}

The JIF of 88 selected journals in the discipline of dentistry ranged between 0.248 and 4.949. The SJR values for corresponding journals ranged between 0.204 and 2.020. Slight differences in ranking positions of journals in the two impact metrics can be seen in Appendix 1. In the cases of three journals, there was no difference in ranking positions. The largest differences in the positions were found for the Journal of Implantology and the Journal of Orofacial Pain as 34 and 33 respectively. A bump chart for the top 10 JCR dental journals (Figure 1) shows that eight journals were also ranked in the top 10 in the SJR list.

Results of Pearson correlation between JIF and SJR scores of selected journals and Spearman correlation coefficient between their ranking positions are given in Table 1 . The values are 0.851 and 0.865 respectively. The most well-known "rule of thumb" to interpret the strength of correlation coefficient was suggested by Cohen (1988). He proposed the values of $0.10,0.30$, and 0.50 as having small, medium and large correlation strength. Many other statisticians disagreed with Cohen and accepted a larger value as a strong effect, starting from 0.60 and sometimes from 0.80 . In the case of dental journals, both null hypotheses were rejected as very high positive correlation was found between the variables. Figure 2 shows scatter plots of the relationship between JIF versus SJR scores and ranks.

\section{DISCUSSION AND CONCLUSION}

A small amount of literature has been produced on the quality of dental journals. The current study is the first of its kind in this discipline that compared and correlated two citation-based journal quality metrics, JIF and SJR. In general, researchers have made two main criticisms of the popular approach for journal ranking. The first criticism is the use of citation-based quantitative measures as a proxy for research quality. To address this, they recommended qualitative methods for this purpose such as perception-based surveys of experts or key informants in specific disciplines. The second criticism is related to the question of the best citation-based metric for the assessment of journal quality. As aforementioned, the scientific community has raised many objections on the use of the oldest and most popular measure, the Thomson Reuters' Journal Impact Factor (JIF).

Later, researchers made efforts to eliminate deficiencies and improve the existing citation-based measures. The creation of SCImago Journal Rank indicator was the outcome of such efforts. Like JIF, it does not use raw citations. However, it uses a complex algorithm to take into account the prestige and quality of the citing sources. The SJR also overcomes many other biases which include geography, language, the journal collection size, self-citations and time window.

Hypotheses tested in the present study reveal that in the case of top dental journals, SJR indicator is highly correlated with JIF. These results are consistent with those of similar studies in general and specific subject areas. Elkins, Maher, Herbert, Moseley, and Sherrington (2010) matched JIF and SJR based rankings of 5503 journals in all subject areas. They found a very strong positive correlation between two metrics (Spearman's rho was 0.89). Other studies on the correlation between these two metrics include: an analysis of 99 
Table 1. Bivariate correlation between two indicators for ranking of dentistry journals

\begin{tabular}{lcc}
\hline Correlation statistic & Coefficient value & Sig. \\
\hline Pearson $r$ between JIF and SJR values & 0.851 & .000 \\
Spearman rho between JIF and SJR rankings & 0.865 & .000 \\
\hline
\end{tabular}

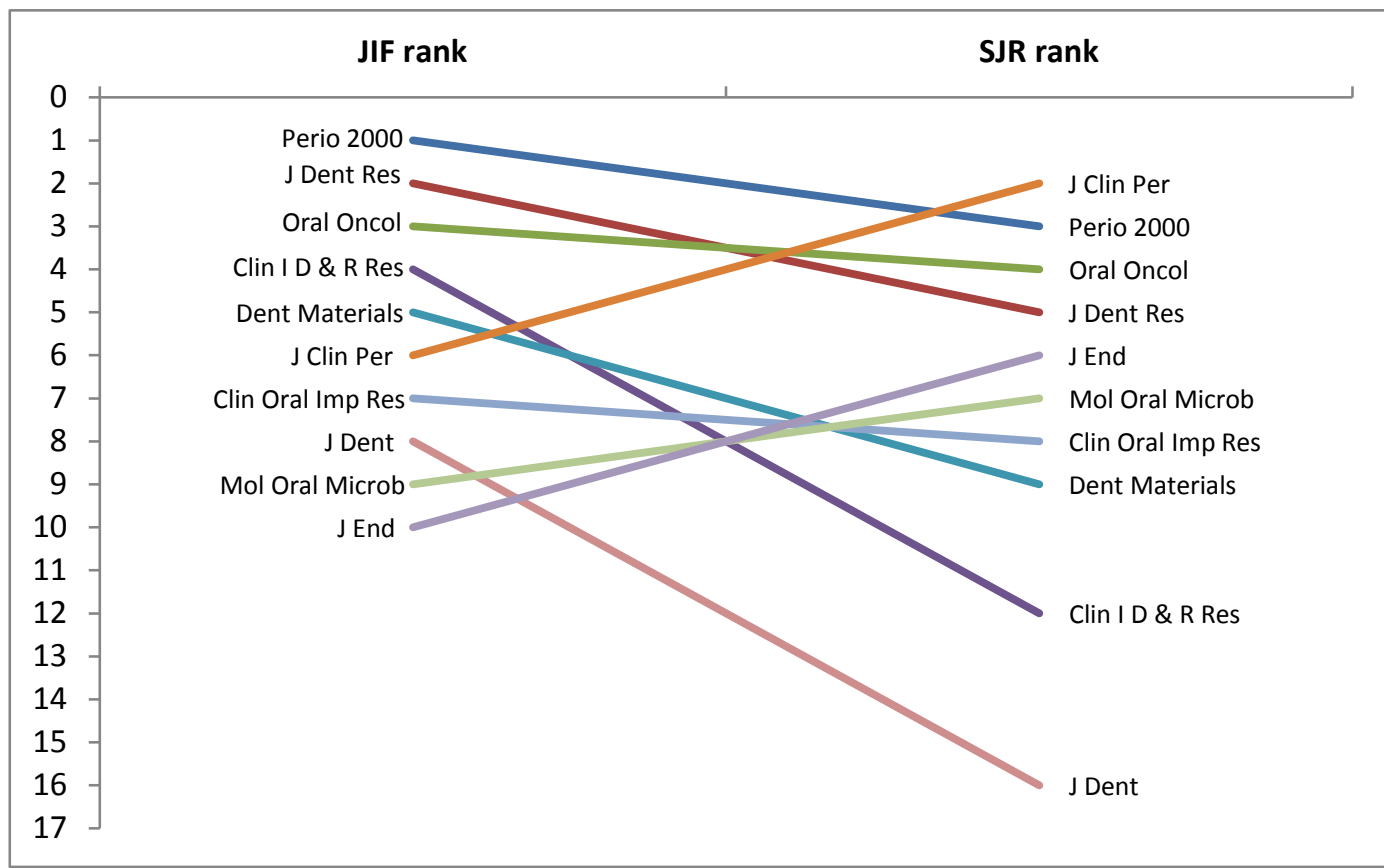

Figure 1. Bump chart for top 10 JIF ranked dentistry journals in comparison with the SJR ranking

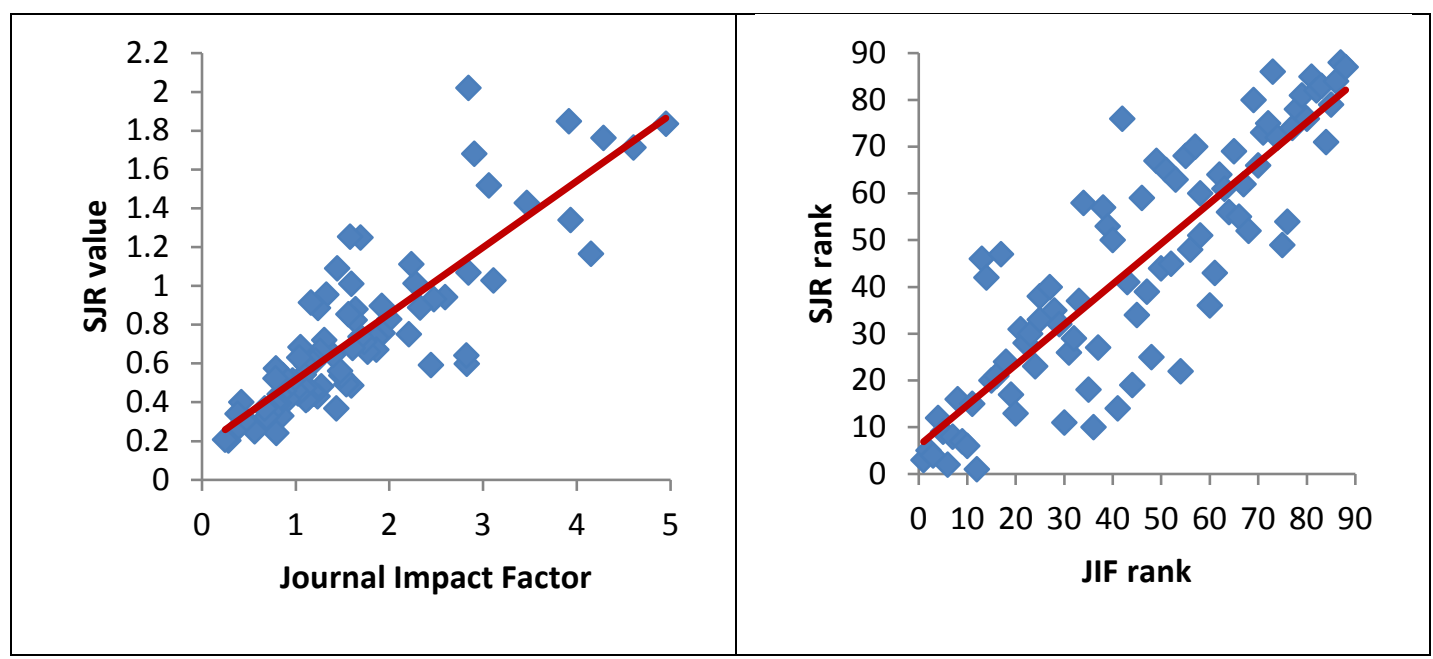

Figure 2. Scatter plots showing the relationship between JIF versus SJR values and rankings, as well as the best-fit lines for $\mathbf{8 8}$ dentistry journals 
randomly selected Brazilian journals (Pearson $r=0.884$ ) (Rocha-e-Silva, 2010), 13 journals of nuclear medicine (Pearson $r=0.919$ ) (Ramin \& Shirazi, 2012), 11 pediatric neurology journals (Spearman rho=0.736) (Kianifar, Sadeghi, \& Zarifmahmoudi, 2014), 50 journals of information and library science (Spearman rho=0.88) (Jacso, 2010), and 259 computer science journals (Spearman rho=0.93) (Sicilia, Sanchez-Alonso \& Garcia-Barriocanal, 2011). We could find only one study in which the correlation between JIF and SJR was negligible (20 journals of anatomy and morphology, Spearman rho=-0.037) (Cantin, Munoz \& Roa, 2015).

We support the recommendation of many authors (for example Leydesdorff, 2009) that the scientific community in the field of dentistry can safely use the freely available SJR indicator as a viable alternative to JIF. Further studies should focus on the validity of SJR as a proxy for research quality.

\section{REFERENCES}

Cantin, M., Munoz, M., \& Roa, I. (2015). Comparison between Impact Factor, Eigenfactor Score, and SCImago Journal Rank indicator in anatomy and morphology journals. International Journal of Morphology, 33(3), 1183-1188.

Cohen, J. (1988). Statistical power analysis for the behavioral sciences. Hillsdale, NJ: Lawrence Erlbaum Associates.

Elkins, M. R., Maher, C. G., Herbert, R. D., Moseley, A. M., \& Sherrington, C. (2010). Correlation between the journal impact factor and three other journal citation indices. Scientometrics, 85, 81-93.

Elliott, D. B. (2014). The impact factor: A useful indicator of journal quality or fatally flawed? Ophthalmic and Physiological Optics, 34, 4-7.

Elsaie, M. L., \& Kammer, J. (2009). Impactitis: The impact factor myth syndrome. Indian Journal of Dermatology, 54, 83-85.

Falagas, M. E., \& Alexiou, V. G. (2008). The top-ten in journal impact factor manipulation. Archivum Immunologiae et Therapia Experimentalis, 56(4), 223-226.

Falagas, M. E., Kouranos, V. D., Arencibia-Jorge, R., \& Karageorgopoulos, D. E. (2008). Comparison of SCImago journal rank indicator with journal impact factor. FASEB Journal, 22, 2623-2628.

Jacso, P. (2010). Comparison of journal impact rankings in the SCImago Journal \& Country Rank and the Journal Citation Reports databases. Online Information Review, 34, 642657.

Journal Citation Reports. (2016). Retrieved from http://ipscience.thomsonreuters.com/product/journal-citationreports/?utm_source=false\&utm_medium=false\&utm_campaign=false

Khurshid, Z. (2014). Measuring the quality of contributions of Saudi authors to LIS journals using Journal Impact Factor (JIF), SCImago Journal Rank (SJR), and Google Scholar Metrics (GSM). The Serials Librarian, 67, 81-98.

Kianifar, H., Sadeghi, R., \& Zarifmahmoudi, L. (2014). Comparison between impact factor, Eigenfactor metrics, and SCImago Journal Rank indicator of pediatric neurology journals. Acta Informatica Medica, 22, 103-108.

Law, R., \& Li, G. (2015). Accuracy of impact factors in tourism journals. Annals of Tourism Research, 50, 19-21.

Leydesdorff, L. (2009). How are new citation-based journal indicators adding to the bibliometric toolbox? Journal of American Society of Information Science \& Technology, 60, 1327-1336.

Oosthuizen, J. C., \& Fenton, J. E. (2014). Alternatives to the impact factor. Surgeon, 12, 239243. 
Ramin, S., \& Shirazi, A. S. (2012). Comparison between Impact Factor, SCImago Journal Rank indicator and Eigenfactor score of nuclear medicine journals. Nuclear Medicine Review: Central \& Eastern Europe, 15, 132-136.

Rieder, S., Bruse, C. S., Michalski, C. W., Kleeff, J., \& Friess, H. (2010). The impact factor ranking: A challenge for scientists and publishers. Langenbeck's Archives of Surgery, 395(Suppl. 1), S69-S73.

Rocha-e-Silva, M. (2010). Impact factor, SCImago indexes and the Brazilian journal rating system: Where do we go from here? Clinics, 65, 351-355.

Rossner, M., Van Epps, H., \& Hill, E. (2007). Show me the data. Journal of Cell Biology, 179, 1091-1092.

San Francisco Declaration on Research Assessment (DORA). (2012). Retrieved from http://www.ascb.org/dora/

Scopus: Content coverage guide. (2016). Retrieved from https://www.elsevier.com/_data/assets/pdf_file/0007/69451/scopus_content_coverage_ guide.pdf.

Seglen, P. O. (1997). Why the impact factor of journals should not be used for evaluating research. BMJ: British Medial Journal, 314, 498-502.

Sicilia, M. A., Sanchez-Alonso, S., \& Garcia-Barriocanal, E. (2011). Comparing impact factors from two different citation databases: the case of computer science. Journal of Informetrics, 5, 698-704. 
APPENDIX 1. COMPARATIVE RANKINGS OF DENTISTRY JOURNALS BY 2015 JOURNAL IMPACT FACTOR AND SCIMAGO JOURNAL RANK INDICATOR

\begin{tabular}{|c|c|c|c|c|}
\hline \multirow[b]{2}{*}{ Journal } & \multicolumn{2}{|c|}{$\begin{array}{l}\text { Journal Impact } \\
\text { Factor }\end{array}$} & \multicolumn{2}{|c|}{$\begin{array}{c}\text { SCImago } \\
\text { Journal Rank } \\
\text { indicator }\end{array}$} \\
\hline & Value & Rank & Value & Rank \\
\hline Periodontology 2000 & 4.949 & 1 & 1.836 & 3 \\
\hline Journal of Dental Research & 4.602 & 2 & 1.714 & 5 \\
\hline Oral Oncology & 4.286 & 3 & 1.764 & 4 \\
\hline Clinical Implant Dentistry and Related Research & 4.152 & 4 & 1.165 & 12 \\
\hline Dental Materials & 3.931 & 5 & 1.339 & 9 \\
\hline Journal of Clinical Periodontology & 3.915 & 6 & 1.848 & 2 \\
\hline Clinical Oral Implants Research & 3.464 & 7 & 1.427 & 8 \\
\hline Journal of Dentistry & 3.109 & 8 & 1.029 & 16 \\
\hline Molecular Oral Microbiology & 3.061 & 9 & 1.517 & 7 \\
\hline Journal of Endodontics & 2.904 & 10 & 1.681 & 6 \\
\hline Journal of Periodontology & 2.844 & 11 & 1.070 & 15 \\
\hline International Endodontic Journal & 2.842 & 12 & 2.020 & 1 \\
\hline Journal of Orofacial Pain & 2.824 & 13 & 0.599 & 46 \\
\hline Operative Dentistry & 2.819 & 14 & 0.641 & 42 \\
\hline International Journal of Oral Science & 2.595 & 15 & 0.942 & 20 \\
\hline Journal of Periodontal Research & 2.474 & 16 & 0.932 & 21 \\
\hline Journal of Oral \& Facial Pain and Headache & 2.444 & 17 & 0.592 & 47 \\
\hline European Journal of Oral Implantology & 2.328 & 18 & 0.888 & 24 \\
\hline Caries Research & 2.278 & 19 & 1.014 & 17 \\
\hline Community Dentistry and Oral Epidemiology & 2.233 & 20 & 1.111 & 13 \\
\hline Clinical Oral Investigations & 2.207 & 21 & 0.752 & 31 \\
\hline Oral Diseases & 2.000 & 22 & 0.828 & 28 \\
\hline Journal of Oral Rehabilitation & 1.926 & 23 & 0.757 & 30 \\
\hline Dentomaxillofacial Radiology & 1.919 & 24 & 0.897 & 23 \\
\hline Journal of Oral Pathology and Medicine & 1.859 & 25 & 0.731 & 33 \\
\hline $\begin{array}{l}\text { International Journal of Oral \& Maxillofacial } \\
\text { Implants }\end{array}$ & 1.859 & 25 & 0.671 & 38 \\
\hline Journal of the American Dental Association & 1.767 & 27 & 0.661 & 40 \\
\hline Archives of Oral Biology & 1.733 & 28 & 0.713 & 35 \\
\hline Journal of Prosthodontic Research & 1.693 & 29 & 0.738 & 32 \\
\hline $\begin{array}{l}\text { American Journal of Orthodontics and } \\
\text { Dentofacial Orthopedics }\end{array}$ & 1.690 & 30 & 1.249 & 11 \\
\hline Orthodontics and Craniofacial Research & 1.640 & 31 & 0.881 & 26 \\
\hline Journal of Oral and Maxillofacial Surgery & 1.631 & 32 & 0.824 & 29 \\
\hline European Journal of Oral Sciences & 1.607 & 33 & 0.681 & 37 \\
\hline Journal of Adhesive Dentistry & 1.594 & 34 & 0.486 & 58 \\
\hline Journal of Cranio-Maxillofacial Surgery & 1.592 & 35 & 1.010 & 18 \\
\hline Angle Orthodontist & 1.579 & 36 & 1.254 & 10 \\
\hline $\begin{array}{l}\text { International Journal of Oral and Maxillofacial } \\
\text { Surgery }\end{array}$ & 1.563 & 37 & 0.854 & 27 \\
\hline Odontology & 1.538 & 38 & 0.493 & 57 \\
\hline International Journal of Prosthodontics & 1.487 & 39 & 0.539 & 53 \\
\hline Journal of Evidence-Based Dental Practice & 1.474 & 40 & 0.563 & 50 \\
\hline European Journal of Orthodontics & 1.440 & 41 & 1.090 & 14 \\
\hline Journal of Oral Implantology & 1.432 & 42 & 0.369 & 76 \\
\hline Gerodontology & 1.396 & 43 & 0.643 & 41 \\
\hline Dental Traumatology & 1.327 & 44 & 0.955 & 19 \\
\hline International Journal of Paediatric Dentistry & 1.303 & 45 & 0.721 & 34 \\
\hline Australian Dental Journal & 1.272 & 46 & 0.482 & 59 \\
\hline $\begin{array}{l}\text { Oral Surgery, Oral Medicine, Oral Pathology and } \\
\text { Oral Radiology }\end{array}$ & 1.262 & 47 & 0.666 & 39 \\
\hline British Journal of Oral and Maxillofacial Surgery & 1.237 & 48 & 0.887 & 25 \\
\hline Journal of Esthetic and Restorative Dentistry & 1.231 & 49 & 0.430 & 67 \\
\hline
\end{tabular}




\begin{tabular}{|c|c|c|c|c|}
\hline \multirow[b]{2}{*}{ Journal } & \multicolumn{2}{|c|}{$\begin{array}{c}\text { Journal Impact } \\
\text { Factor }\end{array}$} & \multicolumn{2}{|c|}{$\begin{array}{c}\text { SCImago } \\
\text { Journal Rank } \\
\text { indicator }\end{array}$} \\
\hline & Value & Rank & Value & Rank \\
\hline BMC Oral Health & 1.210 & 50 & 0.616 & 44 \\
\hline American Journal of Dentistry & 1.194 & 51 & 0.443 & 65 \\
\hline Journal of Public Health Dentistry & 1.182 & 52 & 0.603 & 45 \\
\hline Acta Odontologica Scandinavica & 1.171 & 53 & 0.455 & 63 \\
\hline Korean Journal of Orthodontics & 1.162 & 54 & 0.914 & 22 \\
\hline Journal of Prosthodontics & 1.133 & 55 & 0.421 & 68 \\
\hline Journal of Applied Oral Science & 1.117 & 56 & 0.591 & 48 \\
\hline Journal of Periodontal and Implant Science & 1.108 & 57 & 0.412 & 70 \\
\hline Medicina Oral, Patologia Oral y Cirugia Bucal & 1.087 & 58 & 0.542 & 51 \\
\hline Dental Materials Journal & 1.087 & 58 & 0.474 & 60 \\
\hline Cleft Palate-Craniofacial Journal & 1.050 & 60 & 0.685 & 36 \\
\hline $\begin{array}{l}\text { International Journal of Periodontics and } \\
\text { Restorative Dentistry }\end{array}$ & 1.039 & 61 & 0.631 & 43 \\
\hline Implant Dentistry & 1.023 & 62 & 0.445 & 64 \\
\hline British Dental Journal & 0.997 & 63 & 0.461 & 61 \\
\hline International Dental Journal & 0.967 & 64 & 0.512 & 56 \\
\hline Head and Face Medicine & 0.916 & 65 & 0.416 & 69 \\
\hline Australian Endodontic Journal & 0.885 & 66 & 0.513 & 55 \\
\hline Pediatric Dentistry & 0.872 & 67 & 0.458 & 62 \\
\hline Brazilian Oral Research & 0.859 & 68 & 0.540 & 52 \\
\hline Journal of Advanced Prosthodontics & 0.844 & 69 & 0.330 & 80 \\
\hline Journal of Dental Education & 0.830 & 70 & 0.442 & 66 \\
\hline Quintessence International & 0.821 & 71 & 0.396 & 73 \\
\hline Journal of Oral Science & 0.804 & 72 & 0.387 & 75 \\
\hline Journal of Dental Sciences & 0.795 & 73 & 0.242 & 86 \\
\hline International Journal of Dental Hygiene & 0.791 & 74 & 0.400 & 72 \\
\hline Journal of Orofacial Orthopedics & 0.789 & 75 & 0.574 & 49 \\
\hline European Journal of Dental Education & 0.784 & 76 & 0.524 & 54 \\
\hline Community Dental Health & 0.767 & 77 & 0.395 & 74 \\
\hline Cranio - Journal of Craniomandibular Practice & 0.738 & 78 & 0.351 & 78 \\
\hline Oral Health \& Preventive Dentistry & 0.690 & 79 & 0.325 & 81 \\
\hline $\begin{array}{l}\text { Oral and Maxillofacial Surgery Clinics of North } \\
\text { America }\end{array}$ & 0.670 & 80 & 0.369 & 76 \\
\hline Journal of Clinical Pediatric Dentistry & 0.562 & 81 & 0.250 & 85 \\
\hline Australian Orthodontic Journal & 0.451 & 82 & 0.317 & 82 \\
\hline Oral Radiology & 0.449 & 83 & 0.302 & 83 \\
\hline European Journal of Paediatric Dentistry & 0.421 & 84 & 0.402 & 71 \\
\hline Swedish Dental Journal & 0.381 & 85 & 0.340 & 79 \\
\hline Seminars in Orthodontics & 0.346 & 86 & 0.252 & 84 \\
\hline Journal of the Canadian Dental Association & 0.280 & 87 & 0.204 & 88 \\
\hline $\begin{array}{l}\text { Revue de Stomatologie, de Chirurgie Maxillo- } \\
\text { faciale et de Chirurgie Orale }\end{array}$ & 0.248 & 88 & 0.208 & 87 \\
\hline
\end{tabular}

